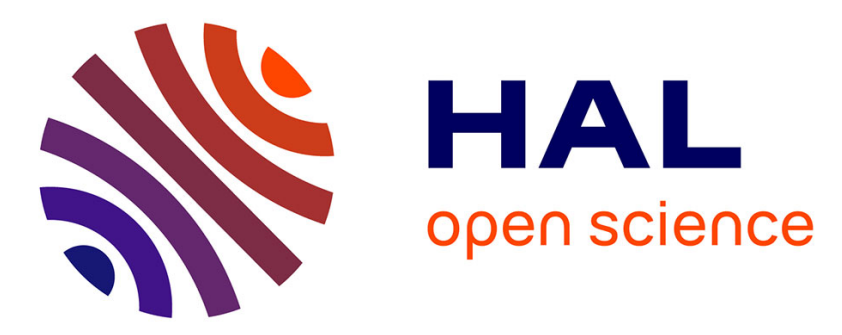

\title{
Quantitative elemental imaging of heterogeneous catalysts using laser-induced breakdown spectroscopy
}

F Trichard, Loic Sorbier, S Moncayo, Y Blouët, Charles-Philippe Lienemann, Vincent Motto-Ros

\section{- To cite this version:}

F Trichard, Loic Sorbier, S Moncayo, Y Blouët, Charles-Philippe Lienemann, et al.. Quantitative elemental imaging of heterogeneous catalysts using laser-induced breakdown spectroscopy. Spectrochimica Acta Part B: Atomic Spectroscopy, 2017, 133, pp.45-51. 10.1016/j.sab.2017.04.008 . hal01581921

\section{HAL Id: hal-01581921 \\ https://hal-ifp.archives-ouvertes.fr/hal-01581921}

Submitted on 5 Sep 2017

HAL is a multi-disciplinary open access archive for the deposit and dissemination of scientific research documents, whether they are published or not. The documents may come from teaching and research institutions in France or abroad, or from public or private research centers.
L'archive ouverte pluridisciplinaire HAL, est destinée au dépôt et à la diffusion de documents scientifiques de niveau recherche, publiés ou non, émanant des établissements d'enseignement et de recherche français ou étrangers, des laboratoires publics ou privés. 


\title{
Quantitative elemental imaging of heterogeneous catalysts using laser-induced breakdown spectroscopy
}

\author{
F. Trichard ${ }^{1}$, L. Sorbier ${ }^{2}$, S. Moncayo ${ }^{1}$, Y. Blouët ${ }^{2}$, C-P. Lienemann ${ }^{2}$, V. Motto-Ros ${ }^{1 *}$ \\ ${ }^{1}$ Institut Lumière Matière UMR 5306, Université Lyon 1 - CNRS, Université de Lyon 69622 Villeurbanne, FRANCE \\ ${ }^{2}$ IFP Energies nouvelles, Rond-point de l'échangeur de Solaize, BP 3, 69360 Solaize, FRANCE \\ *Corresponding author: Dr. Vincent Motto-Ros (vincent.motto-ros@univ-lyon1.fr)
}

Keywords: LIBS, quantification, elemental profiles and images, heterogeneous catalyst, palladium.

\begin{abstract}
Nowadays, the use of catalysis is implied in almost all industrial process. Their use allows improving productivity, synthesis yields and waste treatment as well as decreasing the energy costs. The increasingly stringent requirements in terms of reaction selectivity and environmental standards impose an ever more accurate knowledge and control of their operations. However, the characterization techniques struggle to develop and often require equipment with high complexity. In this paper, we demonstrate a novel elemental approach with an all-optical design allowing quantitative space-resolved analysis to be performed with ppm-scale limit of quantification and $\mu \mathrm{m}$ scale resolution. This approach, based on laser-induced breakdown spectroscopy (LIBS), is distinguished by its simplicity of use, all-optical design, and speed of operation. This work was conducted on palladium-based porous alumina catalyst, used for the selective hydrogenation process in the field of petrochemistry. We report an exhaustive study on the quantification capability of this technique with the possibility to perform imaging measurement over a large dynamical range, typically from few ppm to \%. These results offer new insight into the use of LIBS imaging in the industry and paves the way for innumerable applications.
\end{abstract}




\section{Introduction}

The imaging capability of Laser-induced breakdown spectroscopy (LIBS) represents an attractive way of development for the technique, with innumerable applications in various fields, such as geology [1-3], industry [4-8], surface science [9,10] and biology [11-15]. In LIBS imaging, laser-induced plasma are generated continuously while scanning the sample surface over the region of interest. Elemental images are obtained after extracting the intensity of the interesting species (i.e. atoms, ions or molecules) from each recorded spectrum. This approach has many advantages such as multielemental capability, ease in use, and operation at atmospheric pressure. This is furthermore the only all-optical technique providing space-resolved elemental information with a ppm-scale sensitivity and a $\mu \mathrm{m}$-range resolution [12]. Another asset of the technique lies in its acquisition speed. In LIBS, the acquisition rate can be rather fast since it is only limited by the laser frequency rate and the detector speed. Acquisition rate of up to $\mathrm{kHz}$ has already been demonstrated [16]. Its high acquisition speed combined with its full compatibility with optical microscopy provide LIBS unique features compared to other elemental imaging methods such as laser ablation inductively coupled plasma mass spectrometry (LA-ICP-MS) [17-19], synchrotron radiation microanalysis (SXRF) [20-24], and electron probe micro-analysis (EPMA) [21,25,26]. Although these "gold standard" techniques may have a better sensitivity or spatial resolution, their relatively slow operation speed (generally limited to $\sim 1 \mathrm{~Hz} /$ pixel) makes LIBS very attractive for applications requiring fast imaging, 3D characterization and/or large-scale analysis.

However, being able to provide "quantitative" imaging by LIBS still remains a challenging task and this subject raises a number of issues. First of all, one pixel of the LIBS image corresponds to a unique measurement (i.e. plasma) since the invasive nature of laser ablation, generally, does not allow several measurements to be averaged at one position of the sample. Therefore, the quantification strategy must be deployed without using any statistical information. In addition, the good candidate samples for space-resolved mapping measurements are by nature heterogeneous and may contain 
different matrix and/or strong gradient concentrations. A number of questions must be therefore addressed before each analysis in order to find the best quantification strategy: Does the sample is subject to matrix effect? Does the detection response is linear over all the dynamical range? How to conduct relevant calibration over all the dynamical range, and/or for the different sample phases? What uncertainty can we expect? Etc... These considerations are not specific to LIBS. They are inherent to most of spectroscopic-based imaging techniques, including the previously mentioned. However, although this subject have been discussed in detailed in the literature for LA-ICP-MS [2729], EPMA [30,31] or $\mu$-XRF [28,32], there is no work, to our knowledge, addressing these issues in the particular case of LIBS imaging.

In this paper, we aim at assessing the quantitative capability of LIBS imaging. This work was conducted on palladium-based porous alumina catalysts. This type of sample is ideal in a methodological point of view since Pd concentration covers several orders of magnitude (from wt\% to ppm scale) in a similar matrix. We report for the first time, to our knowledge, a quantitative imaging methodology covering three orders of magnitude. To cover this large dynamical range and overcome eventual saturation effects, a multi-calibration approach is proposed with the use of emission lines with different intensity levels. A methodology based on the distance transform is finally detailed and allows the averaged profiles of Pd to be extracted with a degree of unmatched sensitivity. These results highlight the strong potential of LIBS for quantitative elemental imaging in the field of catalysis and open the way to a wide range of industrial applications.

\section{Material and Methods}

\section{$\underline{\text { Samples }}$}

Samples were prepared by incipient wetness impregnation of an aqueous solution of palladium nitrate (Engelhard). Alumina beads (2-4 mm diameter, total porous volume $0.63 \mathrm{~cm}^{3} / \mathrm{g}, \mathrm{SBET}=70$ $\mathrm{m}^{2} / \mathrm{g}$ ) were put in contact with the solution in a rotating beaker. After impregnation, the catalysts 
were dried at $393 \mathrm{~K}$ overnight and calcined under airflow at $723 \mathrm{~K}$ during 2 hours. This kind of preparation leads to egg-shell distribution of $\mathrm{Pd}$ and then a strong concentration gradient from the border to the center of the beads [18]. The targeted Pd loading was $0.4 \mathrm{wt} \%$. Catalyst beads were then embedded in a black powder resin (STRUERS Polyfast) under temperature $(453 \mathrm{~K})$ and pressure (60 MPa) with a STRUERS ProntoPress-20 mounting press. The sample was polished with SiC paper under water solvent up to the beads diameters and finished with a $1 \mu \mathrm{m}$ diamond suspension. The preparation was finally rinsed with pure ethanol. Different catalyst sections were analyzed by LIBS. The "usual" calibration curve strategy could not be conducted because of the difficulty to find or prepare homogeneous reference samples over all the investigated concentration range of palladium. Several catalyst sections were then analyzed both by LIBS and EPMA with the idea of using EPMA analysis to calibrate the LIBS signal intensities. Previous to each EPMA analysis, the sample surface was coated by a $\sim 20 \mathrm{~nm}$ thick carbon layer.

\section{Electron probe micro-analysis}

EPMA analysis was performed on a JEOL JXA 8100 fitted with five wavelength dispersive spectrometers. Pure Pd (Goodfellow, wire $99.95 \%$ purity) and pure alumina (Goodfellow, sapphire pellet $\varnothing 3 \mathrm{~mm}, 99.9 \%$ purity) were used as standards. Standards were acquired with at least 500000 counts on net peak. On the sample, the electron beam was set to $20 \mathrm{kV}$ accelerating voltage and 240 $\mathrm{nA}$ probe current in order to have a good sensitivity on palladium in a reasonable counting time. The beam was defocused to obtain a $15 \mu \mathrm{m}$ diameter probe. Measurement times were equal on peaks and backgrounds and represent 20 second for each position. Oxygen was dosed by stoichiometry assuming metallic $\mathrm{Pd}$ and $\mathrm{Al}_{2} \mathrm{O}_{3}$ oxide. EPMA on porous samples [33,34] such as catalysts [35] is known to yield a total of concentration lower than $100 \%$. The carbon contamination during the embedding of catalyst beads in resin and surface roughness due to the internal porosity of the sample are the main reasons at the origin of this discrepancy [36]. A careful preparation allows to strongly reduce the carbon contamination. Nevertheless, macroporous catalyst supports such as the 
one employed in this study generate a rough surface yielding a total of concentrations of about 80 to $90 \mathrm{wt} \%$. The concentrations of palladium is then expected to be $10-20 \%$ relative lower than expected. Nevertheless, as there is no obvious reasons that there exists a gradient of roughness along the catalyst beads diameter, concentration profiles along the diameter should remain not distorted. Analysis were performed along the diameter of catalyst sections. The first and last points of each profile was in the surrounding resin to be sure that the whole diameter of the pellet has been measured. Each analysis point was spaced by $15 \mu \mathrm{m}$ leading to an analysis duration of about 70 minutes per section (integration time of twice 20 second per position). In these conditions, the EPMA limit of detection for Pd was estimated at $84 \mathrm{ppm}$ and the limit of quantification at $280 \mathrm{ppm}$.

\section{LIBS imaging}

The LIBS instrument used in this study is shown in figure 1. It has already been described in details elsewhere [37] and only its main components are described in the following. The laser source was a $\mathrm{Nd}$ :YAG emitting $5 \mathrm{~ns}$ pulses at the fundamental wavelength $(1064 \mathrm{~nm})$ with a $10 \mathrm{~Hz}$ repetition rate. The typical pulse energy was $300 \mathrm{~mJ}$ at the output of the laser. The laser beam was spatially filtered using an optical system consisting in an aperture associated with a beam expander to get a "top-hat" profile. After this filtration step, the laser pulse energy was typically $10 \mathrm{~mJ}$. The sample was mounted on a platform which could be translated along three axes by a $X, Y, Z$ motorized system. The travel range of each stage was $50 \mathrm{~mm}$ in each direction. A mechanical shutter was used to control the delivery of laser pulse onto the sample. Laser pulses were vertically focused onto the sample surface by a $\mathrm{x} 15$ magnification reflective objective (LMM-15X-P01, Thorlabs). The plasma radiation was collected by a lens-fiber system, positioned with an angle of about $35^{\circ}$ relative to the sample surface. The collected light was analysed using a Czerny-Turner spectrometer (Shamrock 303, Andor Technology) equipped with a 1200 lines/mm grating and an intensified CCD camera (iStar ICCD, Andor Technology). The ICCD camera was synchronized to the Q-switch of the laser and the spectrum acquisition was performed with delay and gate of $150 \mathrm{~ns}$ and $1 \mu \mathrm{s}$, respectively. The ICCD 
gain was set at $80 / 255$. The width of the entrance slit of the spectrometer was set to $30 \mu \mathrm{m}$. In this configuration, a spectral measurement range of about $30 \mathrm{~nm}$ was accessible with a spectral resolution of $0.15 \mathrm{~nm}$.

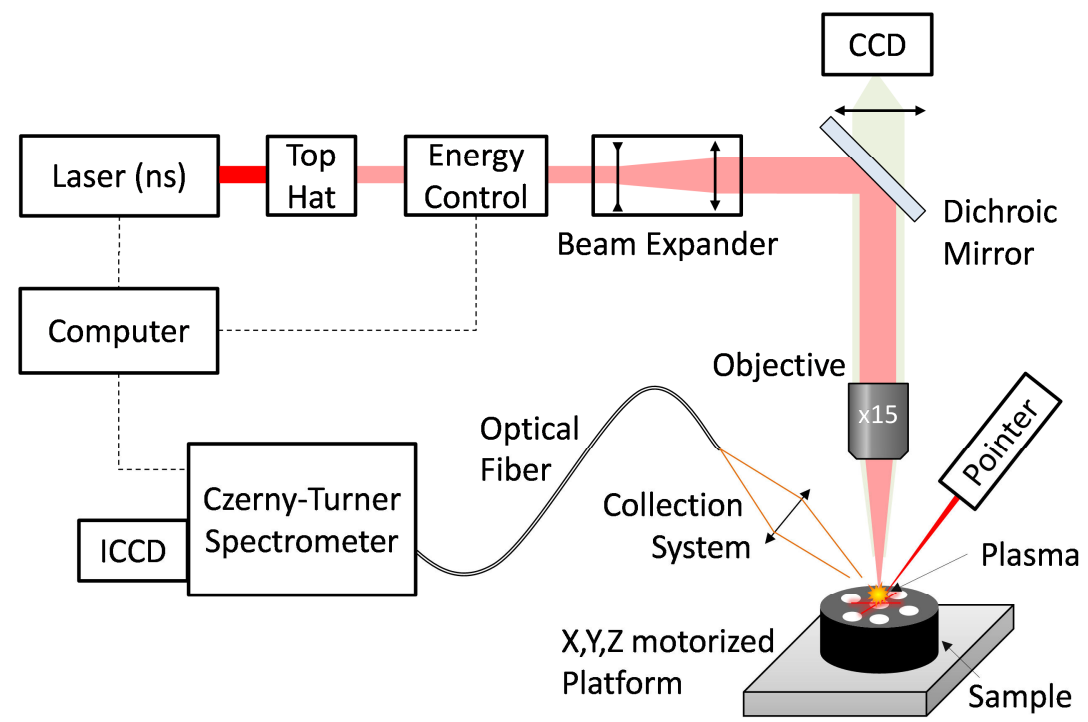

Figure 1: Schematic representation of the LIBS imaging setup.

In mapping mode, the sample movement in the $X$ direction was synchronized with the opening of the beam shutter. The sample surface was scanned, line by line, to cover the region of interest. In this configuration and with regard to the laser frequency rate (i.e. $10 \mathrm{~Hz}$ ), the spatial resolution could be adjusted by changing the speed of the $X$ stage. Besides, the number of pixel per line (i.e. laser shots) is directly related to the opening time of the shutter. Different controls allow the stabilization of experimental parameters throughout the mapping experiment. The laser energy was stabilized by using a servo control loop achieved by using a power meter and a computer-controlled attenuator (ATT266, Quantum Composers). For all experiments presented in the following, the typical pulse energy used was $600 \mu \mathrm{J}$ per pulse and the lateral resolution was $15 \mu \mathrm{m}$. In addition, the vertical positioning of the sample was controlled by using a laser pointer focused obliquely on the sample surface. The position of the laser pointer on the sample surface, imaged by the CCD camera, is indeed a direct monitoring of the focusing distance [37]. Homemade software developed in the 
LabVIEW environment controlled the all system and allowed automated sequences to be set in order to scan the region of interest.

\section{Results}

\section{From spectra to elemental images}

To measure the strongest lines associated with palladium in the UV-visible region, the central wavelength of the spectrometer was set to $350 \mathrm{~nm}$. The spectral range covered in this case, from 338 to $362 \mathrm{~nm}$, also allowed lines originating from $\mathrm{Al}, \mathrm{CN}$ (cyano radical), and Fe to be detected. Examples of single-shot spectra are shown in figure $2 \mathrm{~b}$. They have been recorded in different positions of the catalyst section shown in figure $2 \mathrm{a}$ : $\mathrm{A}$ in the resin, and B-E from the edge to the catalyst center, respectively. As can be seen in the spectrum B, a total of ten atomic lines of palladium were detected. All these lines have various intensity scales, ranging from more than one order of magnitude. It is also noteworthy that contrary to Al, palladium signals strongly decrease from the edge to the center which clearly confirm the strong heterogeneity of this element in the catalyst section. In addition, the $\mathrm{CN}$ molecular band was also observed in the resin due to its organic composition as shown in the spectrum $\mathrm{A}$. Note that the $\mathrm{CN}$ molecular emission interferes with the $\mathrm{Al}$ line but it is still conceivable to extract the aluminum image by applying an appropriate mask.

From there, a careful choice of the emission line had to be addressed. Among the different Pd lines present in this spectral range, different options were possible. The use of a strong line (for example Pd at 340.458) will obviously provide the best limit of detection (LoD) but this line could be more affected by eventual saturation effects that may originate both from self-absorption and/or from the non-linearity of the detection system. In the opposite, a weak line (for example Pd at $343.34 \mathrm{~nm}$ ) will be less affected by saturation effects but also less sensitive. In order to cover the widest possible dynamical range without being affected by saturation effects, our idea was to use two emission lines with different intensity scales. 
a

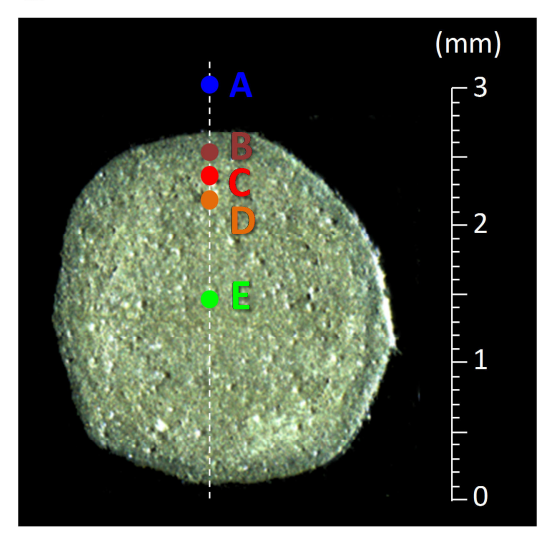

b

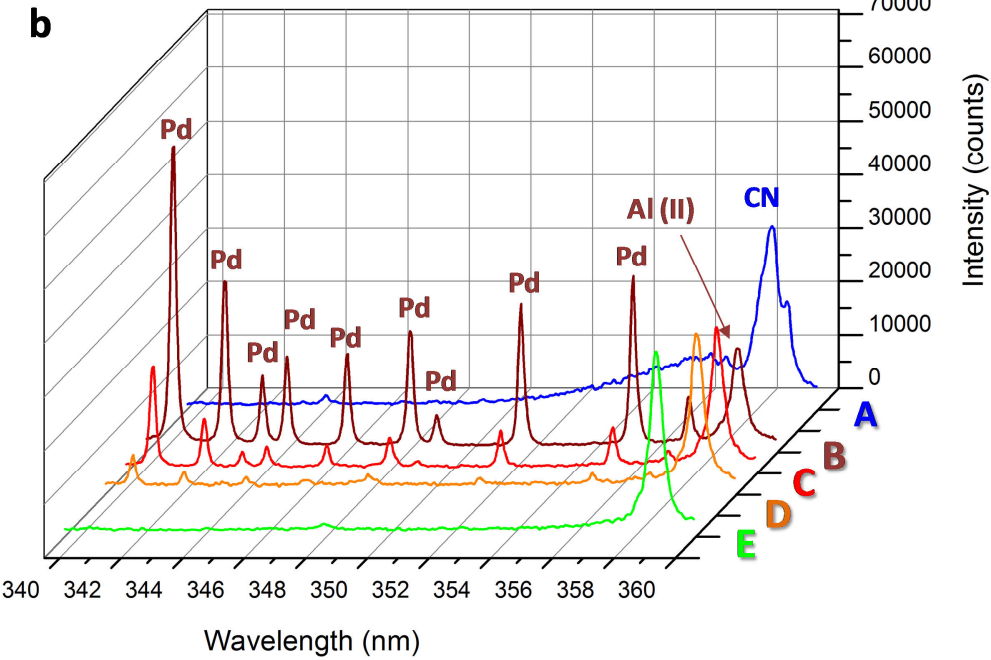

Figure 2: a, Optical image of the catalyst section. b, Typical single-shot LIBS spectra with characteristic emission lines of $\mathrm{Pd}, \mathrm{Al}$ and $\mathrm{CN}$ recorded at five different regions showed in (a).

In addition, we are not immune to spectral interference resulting from undesired contaminations, which may come from surface contaminations (due to the sample preparation and/or sample handling) and/or from the substrate impurity. These eventual contaminants are not necessarily visible on each spectrum since they can be rather heterogeneously distributed in the sample. This aspect is illustrated in figure 3, which shows elemental images of 6 different palladium lines, as well as $\mathrm{Al}, \mathrm{Fe}$ and $\mathrm{CN}$ images. The net intensities of the different emission lines were extracted using a baseline subtraction defined. All treatments were performed with a homemade software dedicated to the intensity extraction and the construction of the elemental images. Among the different Pd images shown in figure 3, it is clear that the Pd images a,b,c appear as interference-free, while images d,e,f suffer from interference with $\mathrm{Al}(\mathrm{g})$, Fe (h) and CN (i), respectively. These results validate our choice to use both $\mathrm{Pd}$ (I) 340.45 and $\mathrm{Pd}$ (I) 343.34, respectively as strong and weak emission lines. The atomic parameters associated to these both lines were extracted from the NIST database [38] and are summarized in table 1 . Note that the upper level of the line at $343.34 \mathrm{~nm}$ is about 2 times higher than the line at $340.45 \mathrm{~nm}$. This weak line is then less affected by self-absorption. 


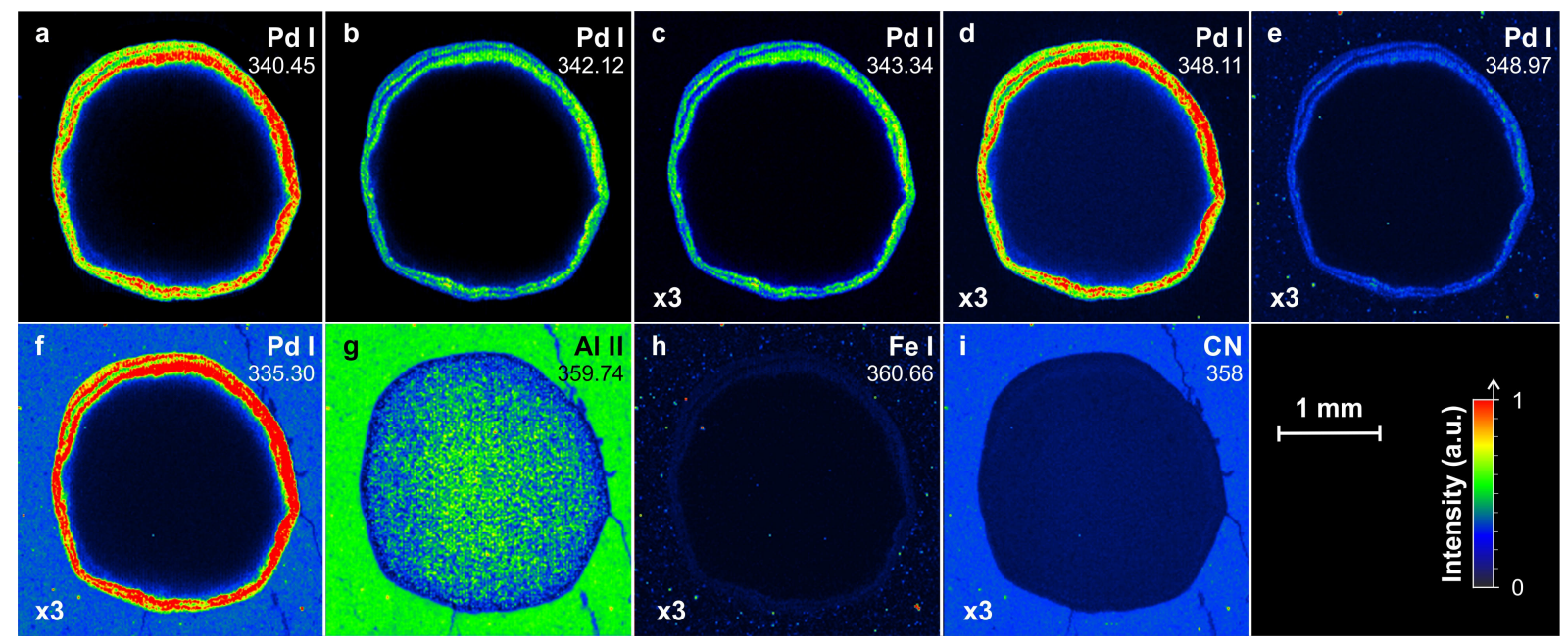

Figure 3: Palladium, aluminum, iron and $\mathrm{CN}$ images of a catalyst section from a) Pd I $340.45 \mathrm{~nm}, \mathrm{~b}$ )

$342.12 \mathrm{~nm}$, c) $343.34 \mathrm{~nm}$, d) $348.11 \mathrm{~nm}$, e) $348.97 \mathrm{~nm}$, f) $355.30 \mathrm{~nm}$, g) Al I $359.74 \mathrm{~nm}$, h) Fe I 360.66

$\mathrm{nm}$ and i) CN emission line at $358 \mathrm{~nm}$. These images are composed by 52500 (250x210) individual pixels. For better clarity a x3 intensity factor was applied to the images c), d), e), f), h) and i).

\begin{tabular}{cccccc}
\hline Species & $\begin{array}{c}\text { Line wavelength } \\
(\mathrm{nm})\end{array}$ & $\begin{array}{c}\text { Intensity at } \\
8000 \mathrm{~K}(\mathrm{a} . \mathrm{u} .)\end{array}$ & $\mathrm{A}_{\mathrm{ik}}\left(\mathrm{s}^{-1}\right)$ & $\mathrm{E}_{\mathrm{i}}-\mathrm{E}_{\mathrm{k}}\left(\mathrm{cm}^{-1}\right)$ & $\mathrm{g}_{\mathrm{i}} \mathrm{g}_{\mathrm{k}}$ \\
\hline $\mathrm{Pd}(\mathrm{I})$ & 340.458 & 24000 & $1.34 \times 10^{8}$ & $6564-35928$ & $7-9$ \\
$\mathrm{Pd}(\mathrm{I})$ & 343.343 & 5000 & $3.28 \times 10^{8}$ & $11722-40839$ & $5-3$ \\
\hline
\end{tabular}

Table 1: Characteristics of palladium emission lines of interest. Value extracted from the NIST database [38]. The line intensities were calculated using a plasma temperature of $8000 \mathrm{~K}$.

\section{$\underline{\text { LIBS calibration }}$}

LIBS measurements were calibrated using space-resolved analysis conducted by electron probe micro-analysis. The use of EPMA was made necessary due to the lack of access to reference samples. A 3 millimeters profile, corresponding to the diameter of a catalyst section (white dot line in figure 2.b), was analyzed by EPMA. This measurement was followed by the acquisition of a full sample image by LIBS (see figure 2.a). LIBS intensities of the two selected Pd emission lines were then extracted following the same profile as EPMA. Both measurements were conducted with the same spatial resolution (i.e. $15 \mu \mathrm{m}$ ) and allowed a "kind" of calibration curves to be built point by point (i.e. pixel by pixel) for both Pd lines. Results are shown in figures 4.a and 4.b respectively for the strong 
and weak Pd lines. The apparent variability observed between LIBS and EPMA can be explained by their different probed volumes. In LIBS, the analysis volume from a single shot measure can be estimated at about $200 \mu \mathrm{m}^{3}$ while the typical probed volume in EPMA is $1400 \mu \mathrm{m}^{3}$. In addition, it may also exist a slight position shift between both measurements.

We can observe from figure 4 that the $\mathrm{Pd}$ line at $340.45 \mathrm{~nm}$ shows a clear saturation effect for palladium concentrations higher than $0.1 \mathrm{wt} \%$, while the intensity of the weak emission line remains linear over all the concentration range, with an intercept close to 0 and a $R^{2}$ coefficient of 0.992 . On the other hand, at concentration lower than $0.1 \mathrm{wt} \%$, the signal of weak Pd line is close or below the noise and only the strong emission line of Pd is detected. The combined used of both Pd lines appears then necessary to cover the entire concentration range. In this way, Pd (I) $343.34 \mathrm{~nm}$ was used for concentration higher than 0.1 wt\% (i.e. intensity $I_{343.34}>1449$ counts) and Pd (I) $340.45 \mathrm{~nm}$ for concentration lower than $0.1 \mathrm{wt} \%\left(\mathrm{I}_{343.34}<1449\right.$ counts $)$.
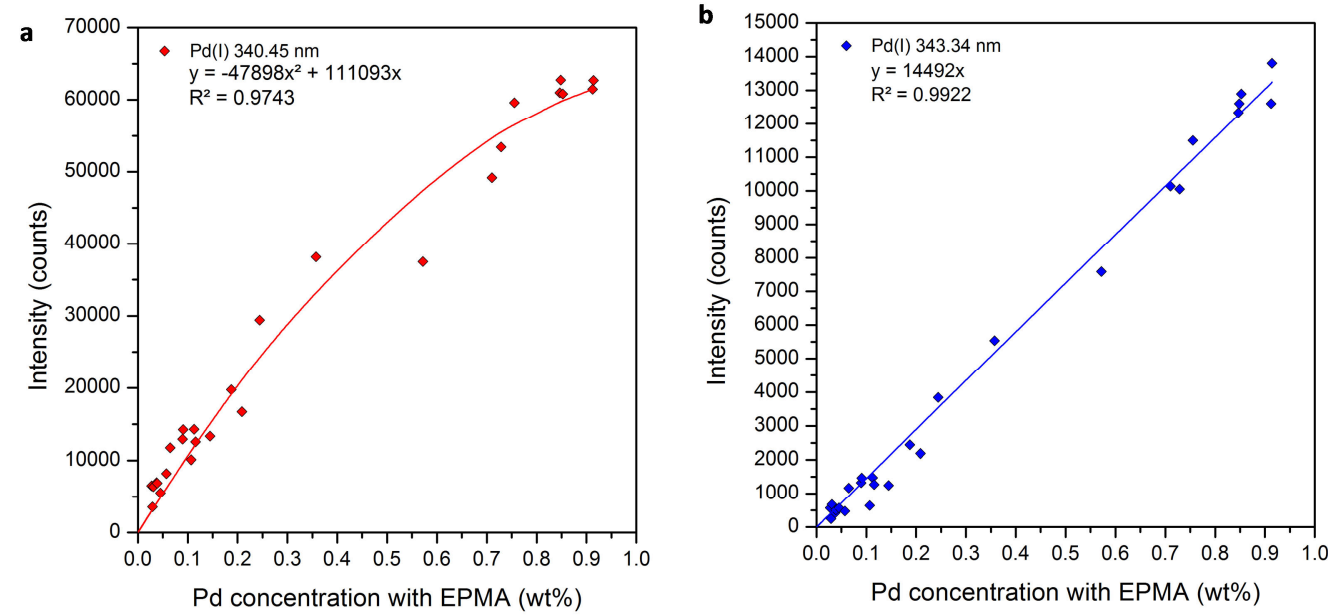

Figure 4: Calibration curves obtained from a, Pd (I) $340.45 \mathrm{~nm}$ and b, Pd (I) $343.34 \mathrm{~nm}$ emission lines on the palladium concentration range above EPMA limit of quantification (i.e. 280 ppm). The regression equation and the determination coefficient $\left(R^{2}\right)$ for each graph are indicated.

\section{Standard (single-shot) profile and quantitative image}


A comparison of the quantitative profiles obtained by LIBS and EPMA with their associated limits of quantification (LOQ) is shown in figure 5. The LOQ were determined for both palladium lines using the $10 \sigma$ method with the following equation [39]:

$$
L O Q_{i}=\frac{10 \times \sigma}{s_{i}}, \quad \text { (1) }
$$

where $\sigma$ corresponds to the measurement noise determined from the spectrum baseline and $\boldsymbol{s}_{\boldsymbol{i}}$ the slope of the calibration curve of the line i. With this relation, LOQs were estimated at $0.06 \mathrm{wt} \%$ and 0.006 wt\% for Pd (I) 343.34 and Pd (I) $340.45 \mathrm{~nm}$, respectively. In figure 5, concentrations higher than LOQ are plotted as continuous line while points correspond to concentrations below the LOQ. The limits of quantification are represented with discontinuous lines. The limit of detection from singleshot analysis was also estimated at $18 \mathrm{ppm}$ according the criterion of three times the noise divided by the slope of the analytical curve. It is shown in figure 5 with a black discontinuous line.

The superposition of both EPMA and LIBS profiles clearly show that LIBS provides a greater degree of information due to its better "analytical" performances. Indeed, the limit of quantification in LIBS is about 5 times lower than the EPMA, which leads to a wider dynamic range. Furthermore, LIBS sensitivity (i.e. LOD) allows the palladium to be significantly detected over the entire profile, even in the central region. In addition to these analytical considerations, it has to be mentioned that the LIBS speed of operation is substantially higher since to obtain these 200 points profiles, the LIBS analysis was 200 times faster than EPMA. Indeed, profile analysis lasts 20 seconds by LIBS while it requires more than an hour by EPMA. 


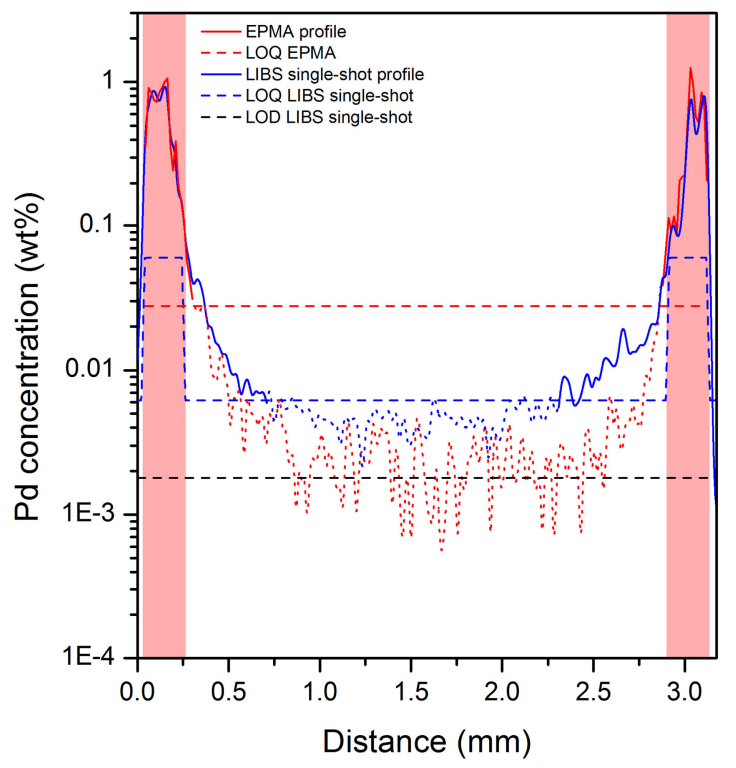

Figure 5: Comparison of quantitative profiles with their limits of quantification obtained by EPMA and single-shot LIBS analysis: using $343.34 \mathrm{~nm}$ (red area) and using $340.45 \mathrm{~nm}$ (white area). The limit of detection of LIBS single-shot analysis is plot in black discontinuous line.

Quantitative images of palladium were then obtained in an equivalent manner. The first step consisted in determining the concentration range associated to each spectrum (i.e. pixel). As previously, the "high" concentration range was defined for intensity $I_{343.34}>1449$ counts and the "low" concentration range for $\mathrm{I}_{343.34}<1449$ counts. The results are shown in figure 6.a illustrating both regions of the catalyst section. Pd concentrations were then retrieved by calibrating high intensity pixels (red area in figure 6.a) using the weak Pd line at $343.34 \mathrm{~nm}$ and the low intensity pixels (white area) with the Pd line at $340.45 \mathrm{~nm}$. The retrieved quantitative image is shown in figure 6.b. A logarithmic false color scale was used in order to help in visualizing the all dynamical range of the palladium concentration. The later covers, in this example, 3 orders of magnitude and extends from few ppm to $w t \%$. The minimum value of the palladium concentration (purple) corresponds to the limit of quantification estimate from a single-shot measurement. Note that a mask, obtained from the $\mathrm{CN}$ image, was also applied in order attribute a null concentration value outside the catalyst section. All this procedure was realized in an automated way using a homemade software developed in the LabVIEW environment. 


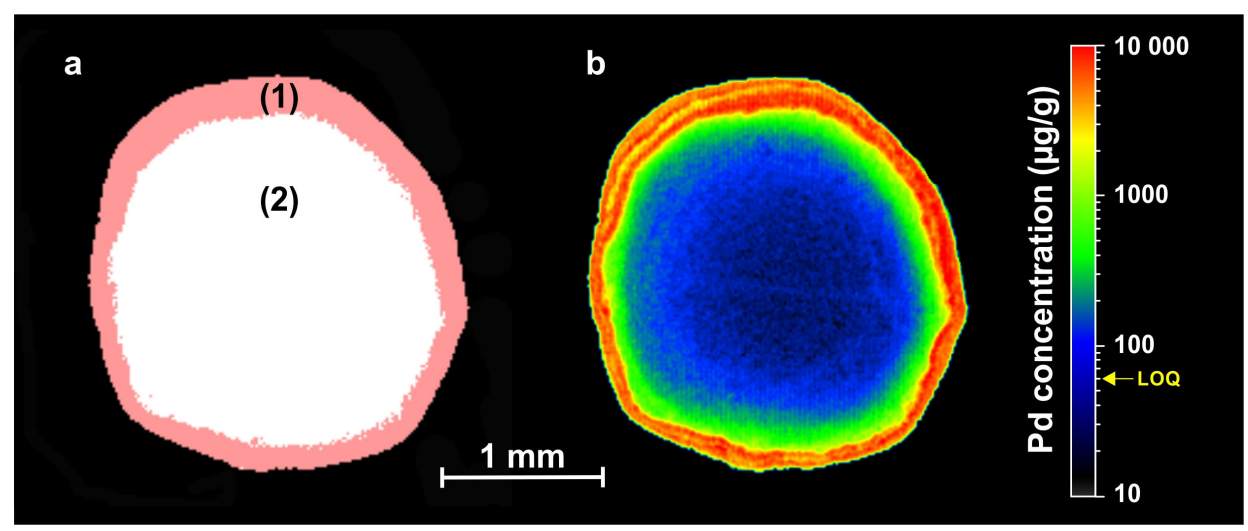

Figure 6: Construction of quantitative image. a) Pd concentration ranges, (1) high level $>0.1$ wt $\%$ and

(2) low level $<0.1 \mathrm{wt} \%$. b) quantitative image of palladium shown with a logarithmic false color scale.

This quantitative image is obtained using both concentration ranges and associated calibration.

\section{Averaged distribution profiles}

It is possible to take the analysis a step further by considering our particular type of samples. In the case of heterogeneous catalysts, the active element (i.e. palladium) penetrates during impregnation in all directions inside the alumina bead, with a concentration gradient which can be considered as uniform with regard to the catalyst surface. It is therefore possible to obtain the global distribution profile of the active element by averaging all the spectra associated to the same distance from the bead's border. This will allow to retrieve the global distribution of Pd inside the catalyst with improved analytical performances due to the averaging.

In order to find all the spectra associated to an equal distance from the edges, we used the distance transform of a mask of a pellet $[40,41]$. This transform, applied to binary images, provide a gray level image with intensity values corresponding to the distance (in pixel unit) to the closest boundary from each point. This transform was then applied to a binary mask obtained from the $\mathrm{CN}$ image. The retrieved distance map was used to find all spectra index located at an equal distance to the catalyst surface. Spectra were then averaged for each equivalent value and the unilateral distribution profile was finally constructed by extracting the net intensities of both palladium lines. Quantitative calibration was applied as described above. The obtained averaged as well as single shot profiles are 
shown in figure 7. As previously, concentrations higher than the LOQ are plotted as continuous line while dot lines represent the concentrations below the LOQ. We can observe a significant improvement of the LOQ as compared to the single-shot profile. In the external region of the catalyst section, this improvement reaches a factor 20. The averaging allows indeed the SNR to be improved as $\sqrt{N}$, where $N$ is the number of averaged spectra, and so the LOQ to be reduced by the factor $1 / \sqrt{N}$. Therefore, LOQ values were not constant throughout the profile since each averaged spectra was obtained from a different number of measurements. In this example, $N$ ranged from 641 at the catalyst border to 5 at the vicinity of the center. In addition, unlike single-shot measurement, the average LIBS quantitative profile allows statistically reliable concentrations to be obtained throughout the catalyst section.

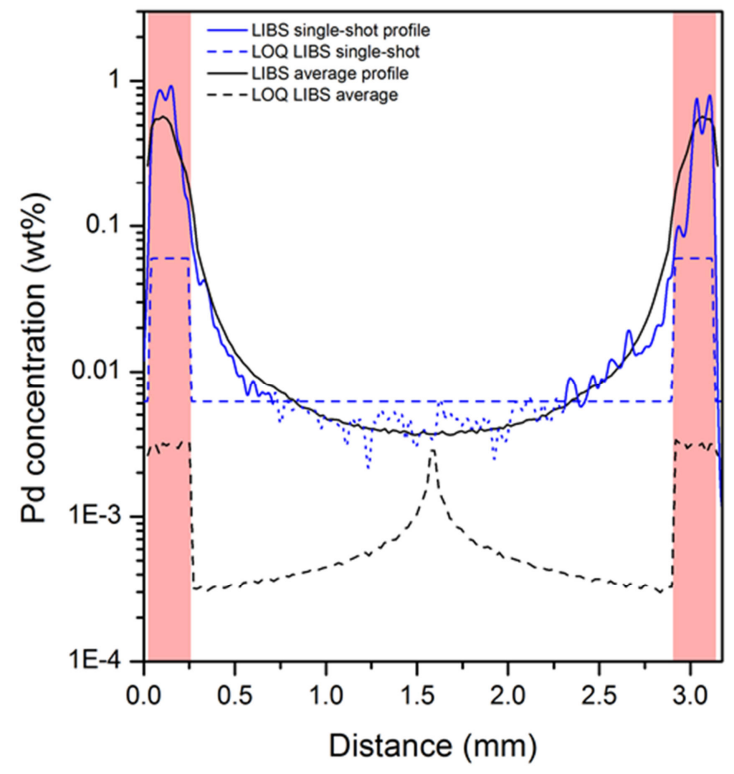

Figure 7: Comparison of single-shot and averaged LIBS quantitative profiles with their respective limits of quantification: using $343.34 \mathrm{~nm}$ (red area) and using $340.45 \mathrm{~nm}$ (white area).

As shown in figure 8 with measurements conducted on other catalyst sections, it finally seems rather relevant to associate both the quantitative image and the global averaged profile. These two results provide indeed very complementary information. First, the image allows a global observation of the active element distribution within the catalyst. Although this image may not be considered strictly 
quantitative due to the single-shot nature of the analysis, it provided the concentration scale of the gradient and informed about possible penetration heterogeneity of the active element. Second, the averaged profile provides a global behavior of the active element distribution within the catalyst. This result is strictly quantitative and statistical measurements uncertainties can be associated. It can be used to understand and model the impregnation processes as well as predict the catalyst performance [18] or do quality control of their production (heterogeneity of batches).
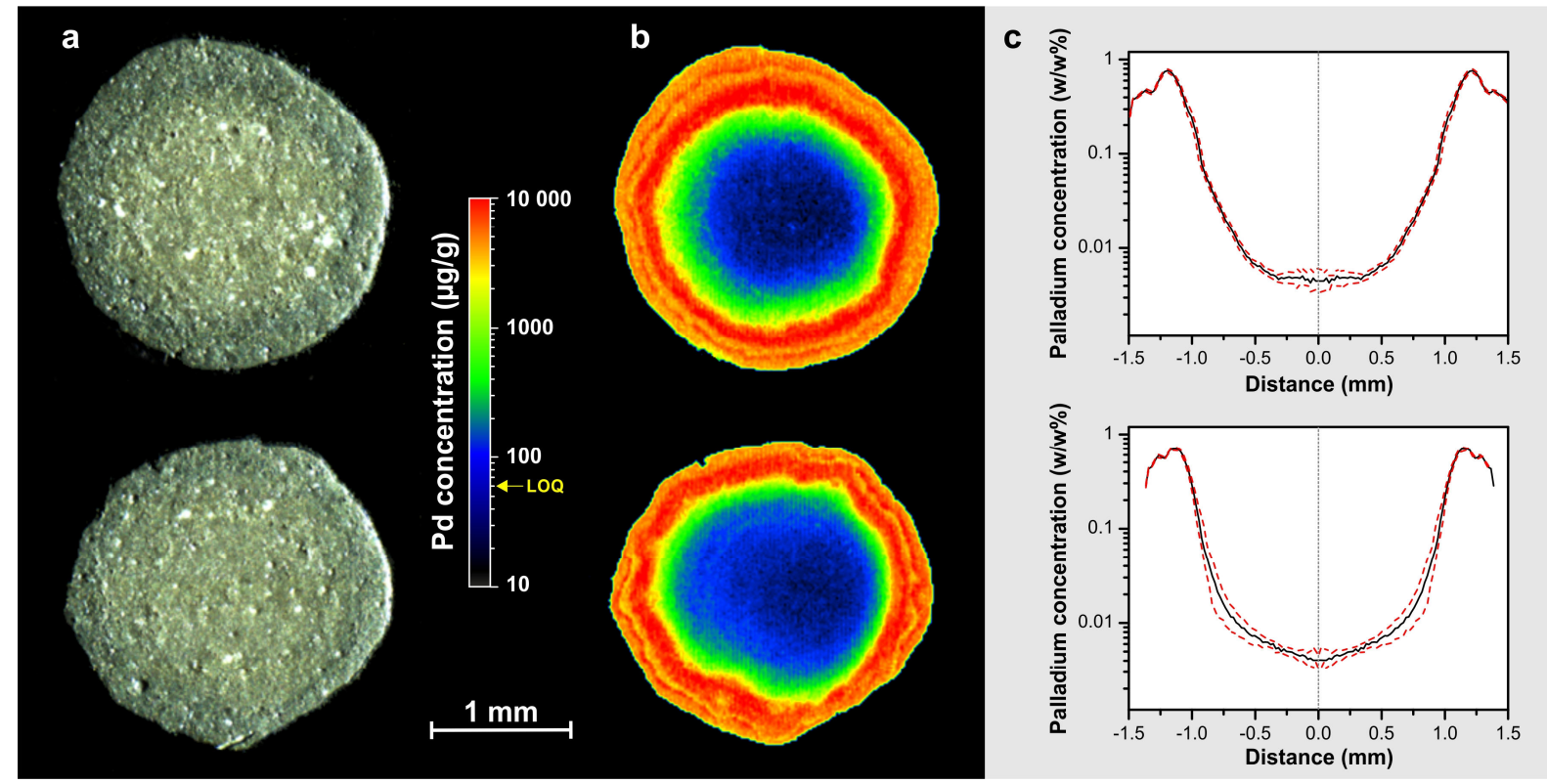

Figure 8: a) Optical images, b) quantitative elemental images and c) averaged profiles of palladium with their respective confidence interval (in dot red) for two different catalyst sections. The confidence intervals were determined by using the following equation $\pm t \sigma$ where $t$ is the Student coefficient (equal to 2 at $95 \%$ confidence) and $\sigma$ the experimental standard deviation. 


\section{Conclusion}

These results demonstrate that the laser-induced breakdown spectroscopy has many advantages and a high potential for quantitative elemental imaging of heterogeneous catalyst. Compared to electron probe microanalysis, LIBS provides, 240 times faster at the same spatial resolution, quantitative elemental images on three orders of magnitude in concentration with about 60 times lower limits of quantification. In addition to these characteristics, LIBS allows to detect elements directly under atmospheric pressure. A disadvantage of this application is the lack of reference samples leading to LIBS measurements calibration with EPMA. However, for making autonomous LIBS quantification protocol, we currently work on the development of several methods to obtain homogeneous reference samples over a wide range of concentration. Furthermore, detection can be further enhanced but with a higher probability of saturation for high concentrations. Even if this work was performed on a model catalyst sample, our LIBS method can be employed in the field of catalysis for predicting and modeling catalysis reaction, for monitoring and characterizing used catalysts from industrial process, in particular, for monitoring poisons and deposits. More generally, this LIBS methodology can also be extended to any application with elements diffusion in materials.

\section{Acknowledgement}

This study has been carried out with financial support from Pulsalys (SATT Lyon Saint-Etienne) in the frame of a maturation project. The authors would like to thank M. Frédéric PELASCINI (CRITT Matériaux Alsace, Strasbourg, France), M. Bruno BOUSQUET (Bordeaux University, France) and Pr. Nai Ho (Hong Kong Baptist University) for fruitful discussions and their help in the redaction of the manuscript.

\section{References}

1. Ma QL, Motto-Ros V, Lei WQ, Boueri M, Zheng L, Zeng HP, Bar-Matthews M, Ayalon A, Panczer G, Yu J (2010) Multi-elemental mapping of a speleothem using laser-induced breakdown spectroscopy. Spectrochimica Acta Part B: Atomic Spectroscopy 65 (8):707-714. 
2. Bassel L, Motto-Ros V, Trichard F, Pelascini F, Ammari F, Chapoulie R, Ferrier C, Lacanette D, Bousquet B (2016) Laser-induced breakdown spectroscopy for elemental characterization of calcitic alterations on cave walls. Environmental Science and Pollution Research:1-8.

3. Sweetapple MT, Tassios S (2015) Laser-induced breakdown spectroscopy (LIBS) as a tool for in situ mapping and textural interpretation of lithium in pegmatite minerals. American Mineralogist 100 (10):2141-2151.

4. Lucena P, Vadillo JM, Laserna JJ (2002) Spatial distribution of catalytically active elements and deactivants in diesel-engine automobile converters by laser-induced plasma spectrometry. Journal of Analytical Atomic Spectrometry 17 (5):548-551.

5. Noll R, Bette H, Brysch A, Kraushaar M, Mönch I, Peter L, Sturm V (2001) Laser-induced breakdown spectrometry - applications for production control and quality assurance in the steel industry. Spectrochimica Acta Part B: Atomic Spectroscopy 56 (6):637-649.

6. Lucena P, Vadillo JM, Laserna JJ (2001) Compositional Mapping of Poisoning Elements in Automobile Three-Way Catalytic Converters by Using Laser-Induced Breakdown Spectrometry. Appl Spectrosc 55 (3):267-272.

7. Lucena P, Laserna JJ (2001) Three-dimensional distribution analysis of platinum, palladium and rhodium in auto catalytic converters using imaging-mode laser-induced breakdown spectrometry. Spectrochimica Acta Part B: Atomic Spectroscopy 56 (2):177-185.

8. Lucena P, Vadillo JM, Laserna JJ (1999) Mapping of Platinum Group Metals in Automotive Exhaust Three-Way Catalysts Using Laser-Induced Breakdown Spectrometry. Analytical Chemistry 71 (19):4385-4391.

9. Menut D, Fichet P, Lacour J-L, Rivoallan A, Mauchien P (2003) Micro-laser-induced breakdown spectroscopy technique: a powerfulmethod for performing quantitative surface mapping on conductive andnonconductive samples. Appl Opt 42 (30):6063-6071.

10. Kim T, Lin CT, Yoon Y (1998) Compositional Mapping by Laser-Induced Breakdown Spectroscopy. The Journal of Physical Chemistry B 102 (22):4284-4287.

11. Sancey L, Kotb S, Truillet C, Appaix F, Marais A, Thomas E, van der Sanden B, Klein J-P, Laurent B, Cottier M, Antoine R, Dugourd P, Panczer G, Lux F, Perriat P, Motto-Ros V, Tillement O (2015) LongTerm in Vivo Clearance of Gadolinium-Based AGuIX Nanoparticles and Their Biocompatibility after Systemic Injection. ACS Nano 9 (3):2477-2488.

12. Sancey L, Motto-Ros V, Busser B, Kotb S, Benoit JM, Piednoir A, Lux F, Tillement O, Panczer G, Yu J (2014) Laser spectrometry for multi-elemental imaging of biological tissues. Sci Rep 4.

13. Gimenez Y, Busser B, Trichard F, Kulesza A, Laurent JM, Zaun V, Lux F, Benoit JM, Panczer G, Dugourd P, Tillement O, Pelascini F, Sancey L, Motto-Ros V (2016) 3D Imaging of Nanoparticle Distribution in Biological Tissue by Laser-Induced Breakdown Spectroscopy. Scientific Reports 6:29936.

14. Moussaron A, Vibhute $S$, Bianchi A, Gündüz $S$, Kotb $S$, Sancey L, Motto-Ros V, Rizzitelli $S$, Crémillieux Y, Lux F, Logothetis NK, Tillement O, Angelovski G (2015) Ultrasmall Nanoplatforms as Calcium-Responsive Contrast Agents for Magnetic Resonance Imaging. Small 11 (37):4900-4909. 
15. Kunjachan S, Detappe A, Kumar R, Ireland T, Cameron L, Biancur DE, Motto-Ros V, Sancey L, Sridhar S, Makrigiorgos GM, Berbeco RI (2015) Nanoparticle Mediated Tumor Vascular Disruption: A Novel Strategy in Radiation Therapy. Nano Letters 15 (11):7488-7496.

16. Bette H, Noll R (2004) High speed laser-induced breakdown spectrometry for scanning microanalysis. Journal of Physics D: Applied Physics 37 (8):1281.

17. Gundlach-Graham A, Burger M, Allner S, Schwarz G, Wang HAO, Gyr L, Grolimund D, Hattendorf B, Günther D (2015) High-Speed, High-Resolution, Multielemental Laser Ablation-Inductively Coupled Plasma-Time-of-Flight Mass Spectrometry Imaging: Part I. Instrumentation and Two-Dimensional Imaging of Geological Samples. Analytical Chemistry 87 (16):8250-8258.

18. Lum T-S, Ho C-L, Tsoi Y-K, Siu C-H, Yue PY-K, Wong W-Y, Leung KS-Y (2016) Elemental bioimaging of platinum in mouse tissues by laser ablation-inductively coupled plasma-mass spectrometry for the study of localization behavior of structurally similar complexes. International Journal of Mass Spectrometry 404:40-47.

19. Becker JS (2010) Bioimaging of metals in brain tissue from micrometre to nanometre scale by laser ablation inductively coupled plasma mass spectrometry: State of the art and perspectives. International Journal of Mass Spectrometry 289 (2-3):65-75.

20. Wogelius R, Manning P, Barden H, Edwards N, Webb S, Sellers W, Taylor K, Larson P, Dodson P, You $H$ (2011) Trace metals as biomarkers for eumelanin pigment in the fossil record. Science 333 (6049):1622-1626.

21. Jacobson AR, Dousset S, Andreux F, Baveye PC (2007) Electron Microprobe and Synchrotron X-ray Fluorescence Mapping of the Heterogeneous Distribution of Copper in High-Copper Vineyard Soils. Environmental Science \& Technology 41 (18):6343-6349.

22. Amati M, Aleman B, Bozzini B, Gregoratti L, Sezen H, Kiskinova M (2016) Characterization of catalytic materials with scanning photoelectron microscopy: Present and future. Surface Science 652:20-25.

23. Zhou X, Wang D, Liu X, Zhang D, Qu S, Ma J, London G, Shen Z, Liu W (2015) 3D-imaging of selective laser melting defects in a $\mathrm{Co}-\mathrm{Cr}-\mathrm{Mo}$ alloy by synchrotron radiation micro-CT. Acta Materialia 98:1-16.

24. Lu H, Chen C, Wang Z, Qu J, Xu D, Wu T, Cao Y, Zhou J, Zheng C, Hu J (2015) Characterization of calcium and zinc spatial distributions at the fibrocartilage zone of bone-tendon junction by synchrotron radiation-based micro $X$-ray fluorescence analysis combined with backscattered electron imaging. Spectrochimica Acta Part B: Atomic Spectroscopy 111:15-22.

25. Sahoo RK, Singh SK, Mishra BK (2016) Surface and bulk 3D analysis of natural and processed ruby using electron probe micro analyzer and X-ray micro CT scan. Journal of Electron Spectroscopy and Related Phenomena 211:55-63.

26. Wilson W, Krakowiak KJ, Ulm F-J (2014) Simultaneous assessment of phase chemistry, phase abundance and bulk chemistry with statistical electron probe micro-analyses: Application to cement clinkers. Cement and Concrete Research 55:35-48.

27. Burger M, Gundlach-Graham A, Allner S, Schwarz G, Wang HAO, Gyr L, Burgener S, Hattendorf B, Grolimund D, Günther D (2015) High-Speed, High-Resolution, Multielemental LA-ICP-TOFMS Imaging: 
Part II. Critical Evaluation of Quantitative Three-Dimensional Imaging of Major, Minor, and Trace Elements in Geological Samples. Analytical Chemistry 87 (16):8259-8267.

28. Wang HAO, Grolimund D, Van Loon LR, Barmettler K, Borca CN, Aeschlimann B, Günther D (2011) Quantitative Chemical Imaging of Element Diffusion into Heterogeneous Media Using Laser Ablation Inductively Coupled Plasma Mass Spectrometry, Synchrotron Micro-X-ray Fluorescence, and Extended X-ray Absorption Fine Structure Spectroscopy. Analytical Chemistry 83 (16):6259-6266.

29. Leach AM, Hieftje GM (2001) Standardless Semiquantitative Analysis of Metals Using Single-Shot Laser Ablation Inductively Coupled Plasma Time-of-Flight Mass Spectrometry. Analytical Chemistry 73 (13):2959-2967.

30. Sorbier L, Gay AS, Fécant A, Moreaud M, Brodusch N (2012) Measurement of palladium crust thickness on catalyst by EPMA. IOP Conference Series: Materials Science and Engineering 32 (1):012023.

31. Dumelié N, Benhayoune H, Balossier G (2007) TF_Quantif: a procedure for quantitative mapping of thin films on heterogeneous substrates in electron probe microanalysis (EPMA). Journal of Physics D: Applied Physics 40 (7):2124.

32. Twining BS, Baines SB, Fisher NS, Maser J, Vogt S, Jacobsen C, Tovar-Sanchez A, Sañudo-Wilhelmy SA (2003) Quantifying Trace Elements in Individual Aquatic Protist Cells with a Synchrotron X-ray Fluorescence Microprobe. Analytical Chemistry 75 (15):3806-3816.

33. Ichinokawa T, Kobayashi H, Nakajima M (1969). Jap JJAP 8 (1563):68.

34. Lakis R, Lyman C, Goldstein J (1992) Proc. 50th Annual Meeting of the Electron Microscopy Society of America (Boston) (San Francisco: San Francisco Press) (1660):61.

35. Lakis R, Vicenzi E, Allen F (1996) Proc. 54th Annual Meeting of the Electron Microscopy.

36. Sorbier L, Rosenberg E, Merlet C (2004) Microanalysis of Porous Materials. Microscopy and Microanalysis 10 (06):745-752.

37. Motto-Ros V, Negre E, Pelascini F, Panczer G, Yu J (2014) Precise alignment of the collection fiber assisted by real-time plasma imaging in laser-induced breakdown spectroscopy. Spectrochimica Acta Part B: Atomic Spectroscopy $92(0): 60-69$.

38. NIST Atomic Spectra Database (2012) Version 5 National Institute of Standards and Technology. http://www.nist.gov/.

39. Mermet J-M (2008) Limit of quantitation in atomic spectrometry: An unambiguous concept? Spectrochimica Acta Part B: Atomic Spectroscopy 63 (2):166-182.

40. Borgefors $\mathrm{G}$ (1986) Distance transformations in digital images. Computer Vision, Graphics, and Image Processing 34 (3):344-371.

41. Rosenfeld A, Pfaltz JL (1968) Distance functions on digital pictures. Pattern recognition 1 (1):3361. 
